Revista Água Viva

\title{
ÀS MARGENS DO TRANSCENDENTAL: O RIO MÍTICO E SUAS BIFURCAÇÕES NOS CONTOS DE FLANNERY O'CONNOR E GUIMARÃES ROSA
}

\author{
IN THE BANK OF TRANSCENDENTAL: THE MYSTHICAL RIVER AND ITS \\ BIFURCATIONS IN FLANNERY O'CONNOR AND GUIMARÃES ROSA'S SHORT \\ STORIES
}

Thiago André de Lacerda Francisco ${ }^{1}$

Recebido em: 03 jan. 2019

Aceito em: 30 mar. 2019

DOI 10.26512/aguaviva.v4i2.21389

RESUMO: Neste artigo pretende-se compreender a atualização do arquétipo do rio, com seu significado mítico, nas obras literárias numa análise comparada dos contos The river (1955) de Flannery O'Connor e A terceira margem do rio (1962) de Guimarães Rosa. Os estudos de Northrop Frye em Anatomia da crítica (1970) e O código dos códigos: a Bíblia e a literatura (1982), em especial sobre os arquétipos e suas manifestações na literatura, bem como o Dicionário de símbolos (1996) de Jean Chevalier servirão como base teórica deste ensaio.

Palavras-chave: Arquétipo; Rio mítico; Literatura comparada; Flannery O’Connor; Guimarães Rosa.

ABSTRACT: In this article it is intended to understand the updating of the archetype of the river, with its mythical meaning, in literary works through a comparative study of the short stories The river (1955) by Flannery O'Connor and The third river bank (1962) by Guimarães Rosa. The studies of Northrop Frye's on Anatomy of criticism (1970) and The great code: the Bible and literature (1982) as well Jean Chevalier's The Dictionary of symbols will serve as a theoretical basis in this analysis.

Keywords: Archetype; Mythical river; Comparative literature; Flannery O'Connor; Guimarães Rosa.

\footnotetext{
${ }^{1}$ Graduando em licenciatura em Artes Cênicas pela Universidade de Brasília (UnB). Atualmente é membro do Grupo de Pesquisa Imagens e $(\mathrm{m})$ Cena (UnB/CNPq) e bolsista do CNPq onde realiza pesquisa sobre as obras do dramaturgo brasileiro Artur Azevedo (1855-1908) com orientação da Prof. ${ }^{a}$ Dr $^{\mathrm{a}}$ Luciana Hartmann. Tem experiência na área de Artes, com ênfase em teatro brasileiro e dramaturgia. E-mail: thiagoxb500@hotmail.com
} 


\section{INTRODUÇÃO}

A imagem do rio é uma das mais recorrentes na literatura universal. No canto XXI da Ilíada de Homero, o rio Xanto, uma divindade antiga para os gregos, batalha contra o herói Aquiles. No Evangelho de Lucas da Bíblia cristã, o rio Jordão surge como uma figura mística onde o filho encarnado de Deus se batiza (Lc. 3.21), numa passagem que para muitos teólogos representa o ponto de contato e manifestação da trindade divina.

Nas suas diversas manifestações dentro das literaturas, o rio é uma figura frutífera, carregados de diversos significados míticos. Este artigo procura investigar estes aspectos em duas obras literárias do século XX, A terceira margem do rio, de Guimarães Rosa (1908-1957) e The river, de Flannery O`Connor (1925-1964).

Em A terceira margem temos a história de um pai que decide ir morar numa canoa, no meio de um rio, deixando sua família aflita, especialmente seu filho que continua a acompanhar a jornada do pai à distância.

The river, de Flannery O'Connor, traz a trajetória do menino Harry Ashfield, que é levado por sua babá Mrs. Connin para ser batizado num rio pelo pregador curandeiro Bevel Summers. Este trabalho procura investigar um ponto de contato entre os dois contos: o rio. Como esta figura arquetípica se apresenta e se estrutura nas duas narrativas, e como os signos presentes no rio se articulam com os personagens de ambos os contos?

Para tal estudo será usado como base o livro Anatomia da crítica de Northrop Frye (1912-1992), em especial seu terceiro ensaio sobre os mitos e arquétipos e de como eles são atualizados dentro das obras literárias, bem como alguns conceitos desenvolvidos na obra $O$ código dos códigos: a Bíblia e a literatura serão úteis para delimitar conceitualmente o significado de mítico. Além destes, o livro Dicionário de símbolos de Jean Chevalier (1906 1993) servirá para investigar os sentidos que envolvem o rio na cultura ocidental.

Por fim, a análise proposta entre dois contos de duas literaturas distintas se encontra dentro do campo da literatura comparada e não se deve perder de vista os problemas metodológicos de uma análise mais estrutural como esta, dentro deste campo literário.

\section{Um arquétipo e duas literaturas}


É da natureza humana, comparar. Ou pelo menos é o que os diversos estudos nas diversas áreas demonstram, a comparação é um método que surge quando se quer estabelecer diferenças e aproximações, ou mesmo quando se deseja atribuir um juízo de valor. Como define Tania Carvalhal em seu livro Literatura comparada: "Comparar é um procedimento que faz parte da estrutura de pensamento do homem e da organização da cultura" (CARVALHAL, 2006, p. 06).

Nesse pequeno livro a autora procura realizar todo o percurso de estudos dentro da literatura comparada na tentativa de mostrar sua relevância para a crítica atual. A literatura comparada, como demonstra a autora, possui em sua gênese uma análise mais ligada à história, em que questões biográficas e culturais acabam por ser o motor desses estudos, preocupado com fontes e influências de um determinado autor de determinada literatura em outra.

As perspectivas ditas "clássicas" em literatura comparada se moldaram, sem dúvida, de acordo com os princípios vigentes no século XIX: historicismo e transferência de métodos de outras ciências para o estudo da literatura. $\mathrm{O}$ chamado positivismo literário vira o século e adentra os primeiros decênios deste, perpetuando na crítica literária como no comparativísmo a inclinação historicista e a atenção voltada para a figura do autor. Pode-se, então, entender a substituição do biografismo do século XIX por um psicologismo vigoroso nas primeiras décadas do século XX (CARVALHAL, 2006, p. 43).

É Rene Wellek (1903-1995), em seu conhecido ensaio (Crise na literatura comparada) quem vai opor-se a esta forma de literatura comparada, uma vez que esses estudos por procurarem identificar fontes e influências entre os autores tornavam-se cada vez mais históricos, se distanciando de uma análise mais próxima do texto literário.

Para o crítico, muitos intelectuais desta área não estão "interessados em literatura, mas na história da opinião pública, em diários de viagem, nas ideias acerca do caráter nacional isto é, na história cultural de modo geral" (WELLEK, 1994, p. 117). Ele então convida os estudos a abandonarem as pretensões históricas e do comparativismo entre as nações, e abraçar a literariedade, ou seja, uma análise estética mais cerrada ao texto.

Como bem coloca Carvalhal, as posições de Wellek, que teve contato com New Criticism norte-americano - escola literária de cunho formalista, isto é, com ênfase ao texto -, ignoram por vezes os sucessos que estudos dentro deste campo interessados na história do desenvolvimento das ideias e na influência de uma cultura estrangeira em outro país tiveram ao longo dos anos - ela cita o exemplo do crítico brasileiro Guilhermino César (1908-1993), que 
foi bem sucedido em seus estudos tradicionais de literatura comparada e que contribuiu com estes para as análises críticas posteriores.

Para este artigo, no entanto, as ideias de Wellek ressoam com maior aceitação, apesar de não ignorar suas problemáticas. Porque assim como o crítico propõe, esta análise se centrará na "estrutura estratificada de signos e significados [que] tenta exatamente ultrapassar a antiga dicotomia entre forma e conteúdo" (WELLEK. 1994, p. 119). Não serão discutidas as intenções dos autores, uma vez que podem acabar por afastar-nos do objeto central que é a obra, mas sim, como este arquétipo se manifesta dentro dos dois contos:

Tenho afirmado que a obra de arte pode ser vista como uma estrutura estratificada de signos e significados que é totalmente distinta dos processos mentais do autor no momento da criação e, portanto, das influências que se podem ter formado em sua mente (WELLEK. 1994, p. 118).

Além disto, a preocupação com a influência de determinada nação em outra não será objeto de estudo deste trabalho. Não serão abandonadas por completo, evidentemente, as peculiaridades de cada nacionalidade nas obras analisadas, mas o foco será o arquétipo do rio, elemento universal da literatura, e sua rede mítica que povoa as duas narrativas.

Antes de adentrar na análise, porém, é importante delimitar o conceito de arquétipo que este artigo estará tratando, uma vez que a comparação se dará através deste. O termo arquétipo possui significados bastante ecléticos no ocidente, sendo o mais conhecido àqueles desenvolvidos pelo teórico psicanalista Carl Jung (1875-1961) - onde o arquétipo é uma imagem primordial de um suposto subconsciente coletivo.

Frye, por sua vez, antes mesmo de começar a tratar sobre os arquétipos em Anatomia da crítica, traz uma definição um pouco diferente e bem mais simples, e também mais ligada aos estudos literários propriamente. Segundo ele o arquétipo é um símbolo enquanto "unidade comunicável, [...]: a saber, uma imagem típica ou recorrente. Entendo por arquétipo um símbolo que liga um poema a outro e assim ajuda a unificar e integrar nossa experiência literária" (FRYE, 1996, p. 101).

Neste sentido, o arquétipo é uma imagem recorrente em obras literárias, que está na base e na estrutura das diversas criações. No entanto, o arquétipo que está em questão (o rio) é carregado de significados míticos, que serão investigados posteriormente durante a análise dos contos. 
Sobre o significado do termo mítico, em sua outra obra Código dos códigos, o crítico canadense traz uma definição bastante útil, pois segundo ele mitos são "antes de tudo mythos, enredo, narrativa, ou, de modo geral, a ordenação de palavras numa sequência" (FRYE, 2006, $\mathrm{p}, 58)$. Assim toda estória seria em princípio um mito. O mítico, no entanto, diz respeito àquelas narrativas que ainda conservam para determinada cultura o seu significado sagrado - que segundo o autor revelam algo de "importante para esta [sociedade] saber, seja sobre seus deuses, sua história, leis ou estrutura de classe" (FRYE, 2004, p. 58).

Assim, apesar do conceito de mito ter, em nosso tempo, a fama de algo irreal ou fantasioso, o mítico é o exato oposto, pois revela verdades pertinentes para uma determinada cultura, como declara o próprio autor: "neste segundo sentido, portanto, o mítico significa o contrário de "não exatamente verdade", significa levar consigo uma seriedade e uma importância especiais" (FRYE, 2004, p. 59).

Assim, o conceito de mítico, que está sendo tratado aqui, está relacionado aos mitos enquanto narrativas sagradas para uma cultura (neste caso, a cultura ocidental) - tanto aquelas que perderam, socialmente e culturalmente, seu peso enquanto estória sagrada (como os mitos gregos, romanos ou latinos), ou aquelas que ainda conservam o seu valor sacro, como os mitos bíblicos ou cristãos.

Desta forma, a comparação entre o rio mítico de O'Connor e Rosa investigará o quanto esta nascente se abastece destas narrativas sagradas, e como ele se atualiza com estes significados dentro destas duas obras do período moderno.

\section{O silêncio e o rio}

Como esperadas, as diferenças entre O’Connor e Rosa são muitas e evidentes. Em O'Connor os personagens têm nomes, o tempo é bastante delimitado e definido - dois dias no total -, a narrativa é contada em terceira pessoa, seguindo um esquema tradicional realista na maneira como são apresentados e expostos os seus personagens. Estes personagens apresentam características grotescas, sendo frequentemente comparados a figuras mórbidas (como a personagem Mrs Connin que no conto é comparada a uma caveira em pelo menos três momentos), ou tomam atitudes violentas e inesperadas ao longo da narrativa. Além de uma moralidade cristã, presente em diversas obras da autora. 
Estes elementos são uma junção de duas vertentes apontadas na obra de O'Connor, o realismo cristão e o gótico sulista, este último um gênero literário forte nos Estados Unidos marcado por personagens grotescos e situações bizarras que buscam gerar pavor no leitor. Nas palavras do crítico Harold Bloom: “A sensibilidade de O’Connor revela uma mescla extraordinária entre o gótico, conforme desenvolvido na cultura do Sul dos Estados Unidos, e um fervoroso catolicismo romano" (BLOOM, 2001, p. 47).

Rosa, no entanto, apresenta uma obra mais claramente identificada como modernista. Ao tratar do romance Grande sertão: veredas, Antônio Candido (1918-2017) faz um comentário instigante sobre "as leis próprias do universo de Guimarães Rosa cuja compreensão depende de aceitarmos certos ângulos que escapam aos hábitos realistas, dominantes em nossa ficção" (CANDIDO, 1978, p. 123). Esta ausência de dependência com "hábitos realistas" pode se estender para todo o universo rosiano, incluindo este conto.

Na obra em questão, um homem passa a morar no meio do rio, e apesar das explicações do narrador - o filho, em primeira pessoa - sobre como ele sobrevivia na canoa, esta é a preocupação menor dentro da narrativa. Os personagens não têm nomes, sendo tratados apenas por pai, mãe, filho e irmã. Assim, há duas diferenças fundamentais com o conto de O'Connor: a narração em primeira pessoa (dando um caráter mais pessoal para a obra) e a ausência de nomes para os personagens (este segundo aspecto será tratado posteriormente).

O que se observa, sobre o estilo dos dois autores, é que enquanto O'Connor está mais próxima de um realismo enquanto estética literária, Rosa tem maior afinidade com universos fantásticos (o que não significa que esteja dissociado do real), pois como pontua o crítico carioca, está é uma das chaves para se compreender todo o universo do escritor mineiro: "E nós podemos ver que o real é inteligível sem o fantástico, e que ao mesmo tempo este é o caminho para o real" (CANDIDO, 1978, p. 139).

Assim, o rio surge então em ambas as narrativas afastando parte das diferenças estéticas, históricas e culturais evidentes nas duas obras e surpreendentemente as aproximam. Pois não é somente a figura central, em torno a qual o enredo concentra toda sua importância, mas é também um lugar significativo para seus protagonistas, representando uma mudança de paradigmas na vida de ambos.

Tanto o pai em Rosa quanto Harry de O’Connor são apresentados como personagens silenciosos. O menino só se manifesta na terceira página do conto e logo no começo é apresentado como calado e silencioso: "The little boy stared at her silently, his nose and eyes 
running. He was four or five. [...] He seemed mute and patient, like an old sheep waiting to be et out"2 (O'CONNOR, 1971, p. 158).

Da mesma forma o pai é descrito em Rosa como quieto. Não ouvimos sua voz em nenhum momento ao longo da narrativa e dele nada sabemos além daquilo que o filho nos revela. "Só quieto"/ "Nosso pai não dizia nada" (ROSA, 2017, p. 384). Em ambos os casos, o silêncio parece representar algo de contemplativo na alma dos personagens protagonistas.

O próprio rio em A terceira margem é descrito como silencioso: "O rio por aí se estendendo: grande, fundo, calado que sempre” (ROSA, 2017, p. 384). É como se algo de religioso e solene envolvesse a figura do rio. E não é o rio que faz o pai silencioso, mas o silêncio parece o atrair para o rio.

Um dos momentos mais emblemáticos deste silêncio, do pai e do rio, é quando a filha decide levar o neto para conhecer o avô. Ela estende a criança nas margens do lugar e espera alguma resposta do pai, mas nada escuta, apenas o vazio e o silêncio:

Mas minha irmã teve menino, ela mesma entestou que queria mostrar para ele o neto. Viemos, todos, no barranco, foi num dia bonito, minha irmã de vestido branco, que tinha sido o do casamento, ela erguia nos braços a criancinha, o marido dela segurou, para defender os dois, o guarda-sol. A gente chamou, esperou. Nosso pai não apareceu. Minha irmã chorou, nós todos aí choramos, abraçados (ROSA, 2017, p. 386).

Em The river, no entanto, o rio é apresentado de maneira distinta. Ao chegar lá para seu batismo, tudo que o jovem Harry escuta é barulho, existem várias pessoas ao redor clamando por cura, e o pregador está fazendo uma espécie de pregação no meio do lugar:

Then he lifted his head and arms and shouted, "Listen to what I got to say, you people! There ain't but one river and that's the River of Life, made out of Jesus' Blood. That's the river you have to lay your pain in, in the River of Faith, in the River of Life, in the River of Love, in the rich red river of Jesus' Blood, you people!"3 (O’CONNOR, 1971, p. 165).

\footnotetext{
2 "Em silêncio, de olhos e nariz escorrendo, o garotinho olhou para a mulher. Tinha quatro ou cinco anos. (...) Parecia tão mudo e paciente como um carneiro velho à espera de ser solto" (O'CONNOR, 2018, p. 30). Serão colocados em rodapé os trechos citados do conto traduzidos por Leonardo Fróes.

3 "Depois erguendo a cabeça e os braços, bradou: "Ouçam o que eu tenho a dizer, minha gente! Existe apenas um rio, que é o Rio da Vida, e ele é feito do sangue de Jesus. É nesse rio que vocês têm de largar seus sofrimentos, no Rio da Fé, o Rio da Vida, o Rio do Amor, o rio do Sangue de Jesus, vermelho e bom" (O'CONNOR, 2018, p. 37).
} 
Ao contrário do rio de Rosa, aqui não é um lugar de silencio e solidão, mas de falatório, com o pregador ostentando excessivamente sua oratória enfadonha, quase que profanando o lugar. No entanto, o silêncio ainda pode ser percebido na atmosfera do jovem Harry e da própria natureza: "Bevel's eyes followed drowsily the slow circles of two silent birds revolving high in the air"4 (O'CONNOR, 1971, p. 165).

Segundo Chevalier e seu Dicionário de símbolos o silêncio "dizem as regras monásticas, é uma grande cerimônia. Deus chega à alma que faz reinar em si silencio" (CHEVALIER; GHEERBRANT, 1995, p. 834). A natureza em The river parece um lugar de contato com o divino, de suspensão do mundo material onde Harry antes vivia. Neste sentido, o silêncio da criança e dos pássaros são os únicos sinais de respeito à cerimônia que se estabelece naquele lugar, naquele rio com toda sua bagagem mítica.

No entanto, tanto o pregador quanto os fiéis maculam o momento com barulho e fanatismo. Eles buscam desesperadamente cura no rio enquanto o pregador canta e ignora o que acontece ao seu redor:

A man in overalls and a brown coat leaned forward and dipped his hand in the water quickly and shook it and leaned back, and a woman held a baby over the edge of the bank and splashed its feet with water. One man moved a little distance away and sat down on the bank and took off his shoes and waded out into the stream; [...] All this time, the preacher sang and did not appear to watch what went on (O'CONNOR, 1971, p. 166). ${ }^{5}$

Essa reação é bastante semelhante à da família em A terceira margem, que convida o padre, soldados e até a imprensa para convencer o pai a sair do rio. Em ambos os casos, o rio parece representar uma viagem interior, um lugar de contato com o divino e por esta razão exige silêncio e contemplação, aspectos cruciais de uma cerimônia, e quem está de fora é incapaz de compreender, e por isso maculam e desrespeitam o momento.

\footnotetext{
4 "Os olhos fatigados de Bevel, enquanto a pregação progredia, seguiam círculos vagarosos que dois passarinhos em silêncio traçavam alto no ar" (O’CONNOR, 2018, p. 38).

5 "Um homem de macacão, com um paletó marrom por cima, dobrou-se sobre o rio, mergulhando e agitando a mão na agua, para logo se endireitar outra vez, e uma mulher foi com um bebê para a beira onde lhe molhava os pezinhos. Um outro, depois de se afastar um pouco para sentar-se à margem e tirar os sapatos, saiu andando água adentro. [...] O pastor cantava, durante todo esse tempo, nem sequer parecia estar notando o que se passava ao redor" (O'CONNOR, 2018, p. 39).
} 


\section{Em algum lugar o "não encontrável"}

No terceiro ensaio do já citado Anatomia da crítica, Frye faz uma análise dos mitos e das imagens arquetípicas dentro do estudo literário. O crítico canadense procura identificar quais seriam os aspectos constituintes comuns a todas as obras literárias. Como o próprio autor deixa claro: “(o objetivo) é dar balanço racional em alguns dos princípios estruturais da literatura ocidental" (FRYE, 1997, p. 135).

A partir daí ele passa a fazer uma análise dos mitos, arquétipos e analogias que para ele são o que derivam a estrutura de toda a literatura.

Os princípios estruturais da literatura, semelhantemente, devem derivar da crítica arquetípica e analógica, as únicas espécies que supõem um contexto mais amplo da literatura como um todo. [...] por isso os princípios estruturais da literatura relacionam-se tão estreitamente com a mitologia e a religião comparativa como os da pintura com a Geometria (FRYE, 1997, p. 136).

Ele começa com um delineamento do mito e do romance realista, separando o mito "num extremo da invenção literária" e "o naturalismo, no outro [extremo], e no meio estendendo toda a estória romanesca" (FRYE, 1997, p. 138), sendo que a estória romanesca está sempre adaptando os arquétipos ou mitos para uma realidade mais plausível dentro de sua construção. "[...] O que pode ser identificado metaforicamente num mito pode apenas ser vinculado, na estória romanesca, por alguma forma de símile: analogia, associação significativa, imagem incidental agregada, e semelhantes" (FRYE, 1997, p. 139).

Seguindo esta linha teórica é possível inferir que The river está bastante próximo daquilo que Frye categoriza como estória romanesca, uma vez que está usando a imagem arquetípica do rio de forma análoga diluindo dentro da realidade do conto. Por outro lado, os procedimentos em A terceira margem são mais complexos do que Frye conceitua nesta obra.

Na também já citada obra $O$ código dos códigos, Frye delimita as chamadas narrativas míticas como pertencentes a uma fase da linguagem chamada de mítica (ou poética). Não aprofundaremos no mérito do conceito, mas basicamente o autor argumenta que nesta fase (que pertence a Ilíada e o Velho Testamento, como exemplos), não havia abstrações e as palavras, em geral, traziam imagens físicas e concretas de “concepções como as de alma, mente, coragem, 
emoção e pensamento" (FRYE, 2004, p. 29). Esta fase será nomeada posteriormente de metafórica, porque trabalha basicamente com estórias (mitos) carregadas de imagens metafóricas.

Um exemplo deste procedimento pode ser dado com a própria Terceira margem do rio que opera num nível metafórico similar as narrativas míticas primitivas - o que é impressionante, tendo em visto que é uma obra do período moderno. É o caso da ausência de nomes para os personagens, que foi citado anteriormente. Esta ausência acentua uma perspectiva mais mítica propriamente - fazendo com que os personagens sejam semelhantes a entidades metafóricas (o Pai, a Mãe) do que indivíduos com nomes e personalidades delimitadas (como Harry Ashfield ou Mrs. Connin), como seria no caso de um conto realista - ou da estória romanesca.

Mais o exemplo mais significativo é o que ocorre nos momentos em que se tenta entender as razões do isolamento do pai no rio: é indecifrável num sentido analógico, não está indicando para nenhum mito especifico fora da obra, mas o isolamento é em si mesmo uma metáfora por uma busca interior. Rosa está operando no nível mítico, onde uma busca interior é materializada num isolamento do corpo físico da sociedade.

The river, por sua vez, que está bastante próximo da estória romanesca, parece mais provável que o conto esteja em busca de uma analogia, no sentido colocado por Frye, onde o rio representa o próprio Cristo. Segundo Frye a imagem de Cristo é a reunião de todos os elementos míticos apocalípticos - a arvore da vida (vegetal), o Cordeiro de Deus (animal), a Pedra Angular (mineral), Deus e Homem (divino e humano) (FRYE, 1997, p. 143). Bevel Summers chama o rio de "O Rio da Vida, feito do sangue de Jesus" (O’CONNOR, 1971, p. 165), não apenas reafirmando o que se encontra no livro de Apocalipse da Bíblia cristã (Ap. 16.6) como também afirmando a posição de Frye sobre o próprio Cristo.

No entanto, o conto que até então não havia dado indícios que confirmaria as analogias feitas pelo pregador, fazendo com que estas soassem apenas como embuste, tem uma mudança significativa quando o menino decide voltar ao rio. Primeiramente, já é evidente o próprio desejo da criança em voltar ao lugar de batismo no dia seguinte após a experiência profunda que ele teve no lugar: "Very slowly, his expression changed as if he were gradually seeing appear what he didn't know he'd been looking for. Then all of a sudden he knew what he wanted to do" (O'CONNOR, 1971, p. 172).

\footnotetext{
6 "Sua expressão começou a mudar bem devagar, como se ele visse aparecer pouco a pouco alguma coisa que nem mesmo sabia estar procurando. Mas de repente ele soube o que queria fazer" (O'CONNOR, 2018, p. 45).
} 
Mais à frente um vislumbre é dado dos motivos que o levaram a refazer o caminho do dia anterior e voltar ao rio:

He intended not to fool with preachers any more but to Baptize himself and to keep on going this time until he found the Kingdom of Christ in the river. He didn't mean to waste any more time. He put his head under the water at once and pushed forward ${ }^{7}$ (O'CONNOR, 1971, p. 174).

É curioso que o menino acredite realmente que mergulhando no rio encontrará o Reino de Cristo. Isso demonstra que o próprio personagem faz uma leitura literal do sentido analógico do rio, enquanto um lugar que representa o próprio Cristo.

Está sendo tratado aqui sobre os significados míticos que o arquétipo do rio carrega, mas é importante delimitar em quais sentidos estes significados foram construídos e estão presentes nos contos. Frye mostra como as águas normalmente representam um "reino de existência baixo da vida humana. [...] Por isso a alma frequentemente atravessa a água ou afunda-se nela ao morrer" (FRYE, 1997, p. 182). Sobre o próprio significado do rio Chevalier traz a seguinte descrição: "o simbolismo do rio e do fluir de suas águas é, ao mesmo tempo, o da possibilidade universal e o da fluidez das formas, o da fertilidade, da morte e da renovação. O curso das aguas é a corrente da vida e da morte" (CHEVALIER; GHEERBRANT, 1995, p. 780).

Como um lugar de "redução ao inorgânico", onde a alma "afunda-se nela ao morrer" e o curso das águas representam "a corrente da vida e da morte", o arquétipo do rio já vem historicamente carregado e todos esses signos parecem estar presentes na narrativa de O’Connor, além da própria figura de Cristo (o rio da vida) que também funciona como análogo ao rio.

No entanto, se o leitor é compelido a acreditar que o rio leva até Deus, num primeiro momento, em seguida, após a criança tentar inúmeras vezes se batizar sem sucesso, o mesmo leitor é movido a essa crença no momento em que a analogia se cristaliza dentro da narrativa numa sequência de enorme beleza poética:

His feet were already treading on nothing. He gave one low cry of pain and indignation. [...] He plunged under once and this time, the waiting current caught him like a long gentle hand and pulled him swiftly forward and down.

\footnotetext{
7 “Não queria mais saber de pastores, nem queria mais bancar o bobo: ele mesmo ia se batizar dessa vez e continuar sempre em frente até encontrar, no rio, o Reino de Cristo. Não querendo mais perder tempo, enfiou a cabeça embaixo d'água e se foi." (O’CONNOR. 2018, p, 46).
} 
For a instant he was overcome with surprise: then since he was moving quickly and knew that he was getting somewhere, all his fury and fear left him (O’CONNOR. 1971, p. 174). ${ }^{8}$

Ao ser pego "por uma mão gentil" e levado para "algum lugar, onde toda sua fúria e medo o abandonariam", o rio assume aqui completamente a sua imagem analógica. A morte por afogamento do menino, mesmo num conto realista, não deve ser lida mais como um evento realista, mas no sentido místico (e mítico) da morte que representa vida, das águas que o levam para a libertação, e a correnteza como "a mão gentil” do próprio Cristo, assumindo por completo a analogia que já vinha se construindo ao longo de toda a narrativa.

E é aqui em que justamente os dois contos tem o seu encontro mais simbólico. Em $A$ terceira margem, como já dito, as razões para a ida do pai ao rio não devem ser lidas de maneira literal. Um dos momentos que fica claro que os motivos para o isolamento do pai não são decifráveis, a não ser numa chave metafórica, é quando o filho se oferece para ficar no lugar dele:

E eu tremi, profundo, de repente: porque, antes, ele tinha levantado o braço e feito um saudar de gesto - o primeiro, depois de tamanhos anos decorridos! E eu não podia... Por pavor, arrepiados os cabelos, corri, fugi, me tirei de lá, num procedimento desatinado. Porquanto que ele me pareceu vir: da parte de além. E estou pedindo, pedindo, pedindo um perdão (ROSA, 2017, p. 387).

Assim, em a Terceira margem, o rio também assume a imagem de uma "corrente da vida e da morte" - um lugar de intercessão entre dois mundos, "da parte de além”. E apesar de o filho acreditar que falhou com o pai porque foi covarde e ter fugido, ao se oferecer para ficar no lugar dele, ele já iniciava seu processo rumo ao rio. Pois, no parágrafo seguinte o filho já manifesta sua mudança interior ao declarar "Sou o que não foi, o que vai ficar calado" (ROSA, 2017, p. 387). O silêncio e a renúncia voltam a aparecer, mas agora o filho fala por si e não sobre seu pai.

\footnotetext{
8 “Seus pés já não pisavam em nada. Um grito baixo, de indignação e dor, lhe veio a boca. [...] Mergulhou mais uma vez, e agora a correnteza que esperava o pegou, qual longa mão delicada, e levemente o levou para a frente e o fundo. Por um instante ele foi tomado de surpresa: depois, como se movia cada vez mais rápido e sabia estar indo a algum lugar, toda a zanga e o medo o abandonaram" (O'CONNOR, 2018, p. 46). O tradutor opta por traduzir fury por zanga, o que é compreensível já que o personagem é um menino, mas que diminui o impacto do termo fúria - também relacionado a irá, um dos sete pecados capitais -, neste momento da narrativa.
} 
E assim se o fim de Harry é carregado de mistério com o menino sendo levado pelas correntezas para "algum lugar", igualmente misterioso é o desfecho do filho sendo carregado, rumo ao "não-encontrável": "rio abaixo, rio a fora, rio a dentro — o rio" (ROSA, 2017, p. 387).

\section{CONSIDERAÇOES FINAIS}

Os dois contos comparados neste trabalho apresentam grandes diferenças estéticas, culturais e regionais, no entanto, o rio que se apresenta nas duas narrativas, como demonstrado, as aproxima. Pois a sua rede poética, arquetípica, mítica e mística se manifesta em ambas as obras.

Se em O'Connor isto se apresenta da maneira delimitada por Frye através de analogias numa estória romanesca, onde o rio representa um ponto de contato com o próprio Cristo, em Rosa os procedimentos são bem mais complexos: o conto transita entre a estória romanesca, mas na maior parte do tempo se comporta de maneira mítica, num nível puramente metafórico, se distanciando de um suposto realismo - mas sendo ao mesmo tempo um caminho para a compreensão do real.

De todo o modo, o que se observa é que ambos os contos bebem da mesma nascente na representação deste rio: como um lugar sagrado, de silêncio e cerimônia, onde vida e morte se confundem, e de contato com algo que a linguagem é incapaz de descrever - "algum lugar" ou “não-encontrável".

E se os procedimentos para representar este rio são distintos, a experiência humana, na figura dos personagens, ante este lugar acaba por ser a mesma, de mistério e redenção.

\section{REFERÊNCIAS}

Bíblia Sagrada: Novo e Velho Testamento. Tradução: João Ferreira de Almeida; revista e corrigida. Várzea Paulista - SP: Casa Publicadora Paulista, 2016.

BLOOM, Harold. Flannery O'Connor. In: Como e por que ler. Tradução de José Roberto O’Shea. Rio de Janeiro: Objetiva, 2001.

CANDIDO, Antônio. O Homem dos Avessos. In: Tese e antítese: ensaios. 3. ed. São Paulo: Nacional, 1978.

CARVALHAL, Tania Franco. Literatura Comparada. 4. ed. rev. e ampliada. São Paulo: Ática, 2006. 
CHEVALIER, Jean; GHEERBRANT Alain. Dicionário de símbolos: (mitos, sonhos, costumes, gestos, formas, figuras, cores, números). Coordenação de Carlos Sussekind. Tradução de Vera da Costa e Silva. 9. ed. Rio de Janeiro, José Olympio, 1995.

FRYE, Northrop. Anatomia da Crítica. Tradução de Péricles Eugene da Silva. São Paulo: Editora Cultrix, 1997.

FRYE, Northrop. O código dos códigos: a Bíblia e a literatura. Tradução de Flávio Aguiar. São Paulo: Boitempo, 2004.

HOMERO. Ilíada. Tradução e introdução de Carlos Alberto Nunes. 25. ed. Rio de Janeiro: Nova Fronteira, 2015.

O`CONNOR, Flannery. The River. In: The Complete Stories of Flannery O`Connor. New York: Farrar, Strauss and Giroux, 1971.

O CONNOR, Flannery. O rio. In: Um bom homem é difícil de encontrar e outras histórias. Flannery O’Connor. Tradução de Leonardo Fróes. Rio de Janeiro: Nova Fronteira, 2018.

ROSA, João Guimarães. A Terceira margem do rio. In: Ficção completa. Rio de Janeiro: Nova Fronteira, v. 2, 2017.

WELLECK, Rene. Crise na literatura comparada. In: Literatura comparada: textos fundadores. Organização de Eduardo F. Coutinho e Tania Franco Carvalhal. Rio de Janeiro: Rocco, 1994. 